\title{
Paradoxes of Business: Towards A Practice Model to Attend to Paradox Tensions in Organizations and Develop the Leaders of Tomorrow
}

Mourad Mechiche

Department of Industrial Management, University of Vaasa

\begin{tabular}{|c|c|}
\hline ARTICLE INFO & ABSTRACT \\
\hline $\begin{array}{l}\text { Keywords: } \\
\text { Paradoxes } \\
\text { Brain plasticity } \\
\text { Behaviour } \\
\text { Learning model }\end{array}$ & $\begin{array}{l}\text { Paradoxes in business i.e. strategy paradoxes, leadership paradoxes, } \\
\text { management and organizational paradoxes are inseparable from } \\
\text { organizations' front-end decision making. Existing literature has } \\
\text { examined these paradoxes in mainly diverse theory driven perspectives } \\
\text { that pointed towards the need to develop a learning cycle to sustain a } \\
\text { practical model to help in navigating the business paradoxes. The aim of } \\
\text { this paper is to uncover the best possible practical approach that would } \\
\text { facilitate the process of navigating the paradoxes in organizations. I } \\
\text { review a vast array of paradox and brain plasticity literature and } \\
\text { conclude that a change in leadership behaviour towards accepting, } \\
\text { embracing, and exercising these paradoxes in a form of a business } \\
\text { simulation is crucial. Thus, I propose a learning model to sustain and } \\
\text { support this practical model. }\end{array}$ \\
\hline
\end{tabular}

\section{Introduction}

Paradox comes from Greek words "Para" which means beyond and "Doxos" which means belief (Kunz, 1998), when connected together make "Beyond belief", that is to say, an opinion that opposes the commonly permitted opinion (Clingerman, 2008). Paradox has become a very intriguing concept nowadays, especially in business organizations. Organizations seek responses that simultaneously attend to competing demands of business such as stability and change (Farjoun, 2010; Stoltzfus et al., 2011), collaboration and control (Sundaramurthy et al., 2003), profit and social responsibility (Margolis and Walsh 2003) (Margolis et al., 2003) and exploration-exploitation (Smith et al., 2005), due to the fast pace in which the business world is developing, new challenges arise and opting for "Either/Or" approach might only be a temporary solution. Opting for a paradox approach might be a more beneficial answer in the long run (Lewis, 2000).

Paradox perspective is an inherent aspect in organizations (Fletcher et al., 1997). Thus, suppressing it means suppressing half of what makes the whole. The need for exploring and exploiting paradox in the business world of today is of utmost importance (Handy, 1995), not to mention that organizations are moving towards a state where they are urged and pressed to become global and local (Reid, 1997), the fast speed of the race to success is ought to seek simultaneously individualism and collectivism (Murnighan et al., 1991), flexibility and efficiency (Adler et al., 1999), in addition to the organizational structures and processes that keep getting more and more complex (Lewis, 2000). Decades of research on exploring the extent of the advantages from two or more opposing polarities when attended to, has given birth to the contingency theory in late 1960s. It offers a response to the faced polarities and encourages surveying the needed conditions for choosing among the polarities in hand (Lawrence et al., 1969; Woodward, 1965). On the other hand, the paradox perspective argues that long term sustainability can only be achieved by perusing divergent end-results 
simultaneously (Cameron, 1986; Lewis, 2000) and the leaders' contribution is a fundamental factor in the organization's destiny (Quinn, 1991; Smith et al., 2011).

However, paradox is confusing, unclear, and ambiguous because the things we expect to behave in a certain manner, do not usually do, moreover, it asks from us to live with two or more opposing ideas simultaneously (Handy, 1995). Studies of paradox have focused on adopting alternative approaches to organizational tensions by exploring, surveying and investigating the possible simultaneous answers that will attend to these tensions, moreover, recent studies have also identified the contrasts that underlie the contradictions and the tensions in organizations; it is not their existence per se that could be considered fruitful or fruitless, but the way they are managed that makes the difference (Smith et al., 2011). Therefore, navigating paradox is about discovering patterns of polarities when juxtaposed, how they can be connected and how they interact while leaders can navigate between these two extremes without them digressing from their purpose along the process (Schuijt, 2011).

Therefore, the aim of this paper is to propose the best possible practical approach that would facilitate the navigation of the paradoxes in organizations. For this matter, I review and synthesize an array of paradox literature supported by literature from neuroplasticity - Human brain ability to alter itself on different levels to satisfy an adopted behaviour (Kolb, 1995)- in order to accept and embrace paradox in business as a tool that helps leaders explore and amplify all available answers using the given business contradictions (Keller et al., 2011), especially in the front-end decision making phase of organizations. Propose a learning model that would contribute in supporting the claim that business paradoxes have to be trained and practiced in a sense of developing a practice environment in which a leader will be faced with all possible organization paradoxes in order to excel in coping with them and ultimately alter their functions to the advantage of business organizations. Finally, to support the implementation of this practice environment in nowadays organizations, I propose a business organizational hierarchy concept which will fuel future research in the quest for an organizational structure that would foster and sustain business paradoxes and considers them as a unity and inseparable part of business organizations decision making.

\section{Leaders, Organizations and Paradox}

Boundaries of organizations are constantly stretched to satisfy the business demands, the business environment is becoming more complex and more permeable to polarities, contradictions and tensions (Boyacigiller, 1990), where this latter leads to ambiguity and uncertainty that cannot easily be pacified (Alvesson, 1993). Moreover, leaders are regularly faced with them and in spite of them make decisions based on a judgement of the more weighted polarity which is not always the possible optimal response (Einhorn et al., 1985), thereby Fletcher and Olwayler concluded that the power of paradox lays in the amplitude of the polarities that can be equal and simultaneously fully present (Fletcher et al., 1997).

The role definition and responsibilities of a leader within the vicinity of an organization and out varies from a source to another and from a theory to another (Gibbins, 2013). Moreover, the power invested in these leaders allows them to steer their organizations to the desired direction, to point out that, leaders are regarded to be the one of the main key factors in shaping the future success of an organization (Culp Gordon et al., 2005), for this reason, one of the many primary concerns of organizations nowadays is attracting talent and retaining it in the organization (Poojary, 2014), henceforth, Quinn (1988) and Van De Ven, (1989) have insisted that organization must develop and nurture a might to attend to the paradox tensions arising in them (Smith et al., 2005), that might be translated by the need of organizations to invest in developing their senior executives abilities to navigate business paradoxes and shape a better future for the business. 
Nonetheless, the existing literature on paradox targets organizations in a form of providing their senior executives with thinking alternatives to reinforce the traditional management practices with end results of adopting proposed perceptions that vary from achieving ultimate competitive advantage (Keller et al., 2011), high performance (Quinn, 1988; Wit et al., 2010), accelerating performance (Price et al., 2017), to solving impossible problem and to get a greater understanding of organizational tensions (Cheal, 2012). The focus on developing a practice environment that would contribute in helping leaders manage the business paradoxes is important. Thanks to Fletcher's pendulum, leaders now can engage in a self-development model that focuses on discovering, perceiving, shifting and defining the handicaps the existing skills of leaders and ultimately be able to self-rate to discover the missing skills that require more attention or development (Fletcher et al., 1997). However, the downside of this model is its vagueness, absence of a meritocracy system and lack motivational incentives. In the long run, a more practical model that would shift the organizations paradoxes from theory driven to a more practical approach that would be the base in the quest for understanding the business paradoxes and use them to the advantage of self-development and to the advantage of the organizations is much needed.

The paradoxes of organizations run like roots deep within organizations, these roots without proper care will wither the success and endanger the existence of these organizations and their future becomes conditioned by the will to adopt a different approach to management and an atypicality in the way of perceiving the world of business and thinking about solutions, a change in perception on how the world is perceived (Quinn, 1988) and last, to embrace the polarities of the paradoxes, connect them together to form an understanding then use it to see through. By doing so, leaders are able to see shortcut to embryonic answers to the problems of today and of tomorrow (Fletcher et al., 1997).

The following figure below is an overview of the main paradoxes that surround organizations in their daily practices. It depicts their interdependence, their inter-relation and how the pressure of their polarities is exercised on both the organization as an infrastructure and on the business purpose this organization was created to achieve.

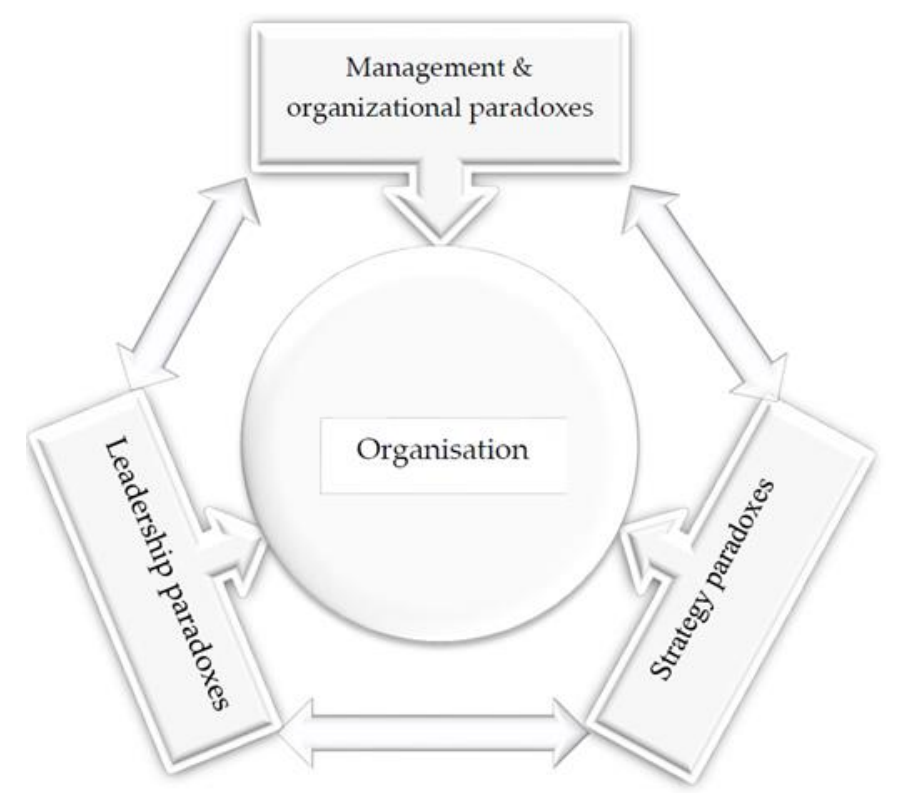

Figure 1. Overview of the main business paradoxes, their inter-dependence and inter-relation to organizations 
To become able handle the tensions and the polarities of these paradoxes, I propose a redefinition of the concept "cope with paradox" in a sense of training and practicing them to be able to navigate between the tensions easily and effortlessly, moreover, Charles Handy (1995) confirmed that, "paradoxes once we are used to them... they are no bother" (Handy, 1995). Correspondingly, to get used to these business paradoxes, one needs to practice on navigating them in the purpose of developing latent abilities that are required to navigate them in the future, because the issue paradox is never about the paradox ambiguity, chaos or uncertainty, it is that the human brain has not yet reached the knowledge level or understanding necessary and not yet acquired the skill set required to grasp its full concept, cope with it, understand it and ultimately navigate it to create long lasting success in not only organizations but also in an individuals' daily life.

\section{Brain Plasticity, Behaviour and Paradox}

In our everyday life we do things in a certain manner and we act in a certain way; hence we behave. As defined by B.F Skinner, Behaviour is a manner in which an individual conducts him/herself (Skinner, 2012). Therefore, the experiences an individual chooses to engage in, shape the pathways of behaviour that in its turn, restructures and rewires the brain and customizes it to the new adopted behaviour; Bryan Kolb confirmed that the brain has the ability to continuously change structure and eventually alter its functions to respond to the environmental changes (Kolb, 1995) which is also known as brain plasticity. If an individual engages in the activity of learning a new skill for instance, an individual who decides to learn how to play a musical instrument, the brain will also engage in restructuring and rewiring itself to satisfy this new adopted behaviour and if the individual continuously and repeatedly engages in this same behaviour, the brain ultimately alters its functions (Kolb, 1995), where the result is constant improvement and ultimately an excel in playing this musical instrument. However, learning to play an instrument by simple observation is an austere void, same as learning how to ride a bicycle simply by watching others do it. the practice is an important factor that contributes in the learning process (Seibert et al., 1999) and also in the plasticity of the brain (Kolb et al., 1998) that supports the purpose of this work on the condition of changing our perception by changing our behaviour towards exercising ourselves and practice to navigate the paradoxes in business and confirm Charles Handy's statement that once we get familiarized and used to paradox, understanding them and using them will not be a bother.

Therefore, the two important pre-required skills that one needs to start training, in order to begin the journey to exercise navigating the business paradoxes, develop and nurture the required thinking skills that will contribute in grasping the meaning of existence of business paradoxes are as follows:

- Paradoxical cognition: In other words, the ability to recognize tensions. While contemplating as a leader on the organization's issues the need to exercise a thinking process that supports the idea issues in business organizations tend to have more than one side, rather, they are presented in polarities shall be instinctively cognized when confronted with even in the easiest of problems.

- Paradoxical observation: This skill is required when confronted with paradoxical problems, one should develop patterns based on the manner in which they were solved, what would have been solved using traditional thinking could be one half of an answer, the other half of this answer becomes apparent when juxtaposed with the opposite of the answer from the traditional thinking. It requires a little bit of unconventionality in the process since the existing rules are relished and conclusions might be seen as nonsense and/or crazy.

These skills are to create an atmosphere in which a leader will not be satisfied with simple answers under the pretext that paradoxes are vague ambiguous and there is no time for them in an organization (Schuijt, 2011), rather, a leader will invest the efforts and the time necessary 
to explore every possible answer for a given issue and learn from these answers by developing patterns of resolution for future uses.

Nonetheless, Kolb and Teskey have confirmed that practically every experience is qualified to alter the brain even for at least a brief period of time. Henceforth, these changes are per se unpredictable since à priori, the changes themselves cannot be foretold. On this matter, Kolb and Teskey have confirmed that understanding paradoxes will contribute greatly in developing a better understanding of the way in which the brain functions, taking in consideration that, many of the changes that happen in the brain are qualified as paradoxical and inadequately understood by scientists (Kapur, 2011).

Therefore, this proposed "navigating paradoxes" approach in business strays from the already existing models, approaches and/or strategies [i.e. Poole \& Van de Ven 1989: 565 that provided "modes of paradox resolution" approach to systemize paradox management in organization; Fletcher's pendulum and "Mastering the contradictions of organizational life" by Quinn (1988:25-109)] to shift it to a more practical approach that would be based on the already existing theories as well as involve the nowadays technologies such as artificial intelligence, management simulations and business simulations in order to provide managers, leaders, academia and future leaders the opportunity to position themselves in a multibillion organization and shoulder the burdens of the responsibilities of such a position in a form of a training platform. The leader should have the opportunity to experiment with both the polarities of the business paradoxes they will be faced with during the training and the results of his/her made decisions will be drawn based on a simulation of real-life events.

This atypical approach to navigate business paradoxes within the premises of this proposed model shall be based on the following learning process steps

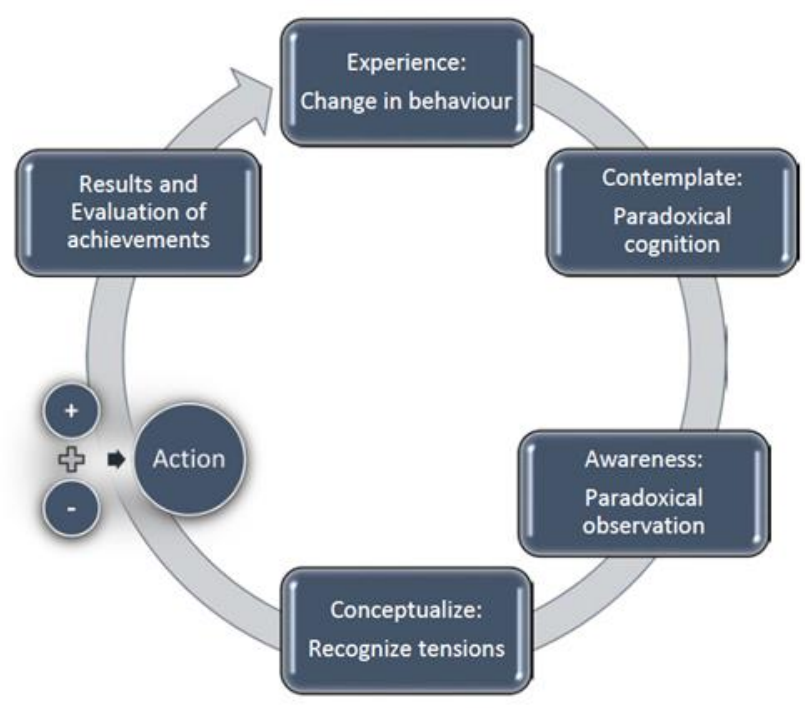

Figure 2. Learning process based on continuous training using the proposed stimulus model. (Model base adopted from Kolb's Experiential Learning Cycle)

This learning process will be the base to develop an environment to help train leaders to cope with business paradoxes, the quest to find the will to change behaviour, accept that paradoxes are inseparable from business (Stevens, 2010) in particular and from daily life in general and to recognize the need to develop paradoxical thinking abilities by facing head to head the paradoxes of business is of utmost importance.

Moreover, there is nothing that compels organizations or their management to adopt paradox in their decision making, to some extent it is very true and the reason it is true is, paradoxes do not provide us with easy alternatives and do not allow us simple or oversimplified answers, it 
asks us to live simultaneously with opposite tensions (Keller et al., 2011), and it confuses us. Our quest to find the right strategy, right approach and right method to run organizations in a fast changing business world, have helped us develop patterns which we recognize as right or as foundation or buoys to our future, and the rest that we do not conceive is just dysfunctional that needs to be suppressed or eliminated as Charles Handy goes on to say that, "I used to think that paradoxes were the visible signs of an imperfect world" (Handy, 1995). Paradox, by exposing oneself to it in order to use it, one becomes the interface of the paradox contradiction's manifestations, hence, the leader engages these contradictions by using paradoxical frames Thinking patterns that support the acceptance of paradoxical tensions (Smith et al., 2005)-. Thus, a magnification and an amplification of the quotient of answers or solutions to a given issue. Moreover, Quinn goes on to sum this latter up by stating that, “...embryonic solutions emerge from individuals flirting with doubt and disorder" (Quinn, 1988), this lays down frontiers for decision-making, managerial and organizational dogmas, as well as it opens doors to adopting a multidimensional organization culture where an answer that does not satisfy two divergent goals is considered just not enough.

As a result, considering all the above mentioned, organizations are more than compelled to adopt paradox and their management to learn and invest in their leaders to acquire the right skill set needed to cope with the business paradoxes to be able to achieve better work performances, better organizational health, more knowledge, broader horizons and many other advantages that are yet to be discovered.

\section{Conclusion}

In summary, paradoxes manifestation in business will only increase with the fast pace of changes in the business world and a need to adopt a working behaviour that would drive the organization's culture and seek answers beyond rationality is a must, not to mention that a leader plays a key role in an organization's success (Culp Gordon et al., 2005). Therefore, the need to invest in developing an environment that would facilitate the process of practicing and exercising in the best possible way to navigate the paradox tensions in business is critical. My goal in this paper is to open the research gates for this new stream of navigating the business paradoxes by exercising and I hope that my work contributes in understanding and navigating the challenges of future business complexities as well as boost the knowledge of paradox in business to a new level on understanding. Taking in consideration that the details of the required environment to realize this project are both documented in my master's thesis and in my $\mathrm{PhD}$ proposal, I hope I will get a chance to peruse this topic further and help in making the business world more successful.

\section{References}

Adler, P. S., Goldoftas, B., \& Levine, D. I. (1999). Flexibility versus efficiency? A case study of model changeovers in the Toyota production system. Organization Science, 10(1), 4368 .

Alvesson, M. (1993). Organizations as Rhetoric: Knowledge-Intensive Firms and the Struggle with Ambiguity. Journal of Management Studies, 30(6), 997-1015. doi: 10.1111/j.14676486.1993.tb00476.x

Boyacigiller, N. (1990). The Role of Expatriates in the Management of Interdependence, Complexity and Risk in Multinational Corporations. Journal of International Business Studies, 21(3), 357-381.

Cameron, K. S. (1986). Effectiveness as Paradox: Consensus and Conflict in Conceptions of Organizational Effectiveness. Management Science, 32(5), 539-553. 
Cheal, J. (2012). Solving Impossible Problems: Working Through Tensionsand Paradox in Business. Crown House Publishing.

Clingerman, F. (2008). The Uses of Paradox: Religion, Self-Transformation, and the Absurd By Matthew Bagger. Religious Studies Review, 34(2), 85-85. doi: 10.1111/j.17480922.2008.00264_1.x

Culp Gordon, \& Smith Anne. (2005). Leadership Effectiveness and Behavior. Leadership and Management in Engineering, 5(2), 39-48. doi: 10.1061/(ASCE)1532-6748(2005)5:2(39)

Einhorn, H. J., \& Hogarth, R. M. (1985). Ambiguity and Uncertainty in Probabilistic Inference. Psychological Review, 92(4), 433-461.

Farjoun, M. (2010). Beyond Dualism: Stability and Change as a Duality. Academy of Management Review, 35(2), 202-225. doi: 10.5465/AMR.2010.48463331

Fletcher, J., \& Olwyler, K. (1997). Paradoxical Thinking: How to Profit from Your Contradictions. Berrett-Koehler Publishers.

Gibbins, S. (2013). Leadership From Within. Newborn and Infant Nursing Reviews, 13(3), 104. doi: 10.1053/j.nainr.2013.06.003

Handy, C. B. (1995). The Age of Paradox. Harvard Business Press.

Kapur, N. (2011). The Paradoxical Brain. Cambridge University Press.

Keller, S., \& Price, C. (2011). Beyond Performance: How Great Organizations Build Ultimate Competitive Advantage. John Wiley \& Sons.

Kolb, B. (1995). Brain Plasticity and Behavior. Psychology Press.

Kolb, B., \& Whishaw, I. Q. (1998). Brain plasticity and behavior. Annual Review of Psychology, 49(1), 43.

Kunz, G. (1998). The Paradox of Power and Weakness: Levinas and an Alternative Paradigm for Psychology (1st edition). Albany: SUNY Press.

Lawrence, P. R., \& Lorsch, J. W. (1969). Organization and environment; managing differentiation and integration. Homewood, Ill.: R.D. Irwin.

Lewis, M. W. (2000). Exploring Paradox: Toward a More Comprehensive Guide. Academy of Management Review, 25(4), 760-776. doi: 10.5465/AMR.2000.3707712

Margolis, J. D., \& Walsh, J. P. (2003). Misery Loves Companies: Rethinking Social Initiatives by Business. Administrative Science Quarterly, 48(2), 268-305.

Murnighan, J. K., \& Conlon, D. E. (1991). The Dynamics of Intense Work Groups: A Study of British String Quartets. Administrative Science Quarterly, 36(2), 165.

Poojary, U. P. (2014). Key Determinants of Attracting and Retaining Managerial Talents:An Empirical Study. Anveshana, 4(1), 29-52.

Price, C., \& Toye, S. (2017). Accelerating Performance: How Organizations Can Mobilize, Execute, and Transform with Agility. John Wiley \& Sons.

Quinn, R. E. (1988). Beyond rational management: mastering the paradoxes and competing demands of high performance. Jossey-Bass.

Quinn, R. E. (1991). Beyond Rational Management P: Mastering the Paradoxes and Competing Demands of High Performance (New Ed edition). San Francisco: John Wiley \& Sons. 
Reid, M. E. (1997). The Global-Local Paradox: From Local to Global and Back Again. Urban Affairs Review, 33(1), 134-140. doi: 10.1177/107808749703300106

Schuijt, L. (2011). Paradoxes in leadership development as a pathway to spirituality. Retrieved from https://www.lenetteschuijt.nl/paradox-as-pathway-to-spirituality/?lang=en

Seibert, K. W., \& Daudelin, M. W. (1999). The Role of Reflection in Managerial Learning: Theory, Research, and Practice. Quorum.

Skinner, B. F. (2012). Science And Human Behavior. Simon and Schuster.

Smith, W. K., \& Lewis, M. W. (2011). Toward a Theory of Paradox: A Dynamic Equilibrium Model of Organizing. Academy of Management Review, 36(2), 381-403. doi: 10.5465/AMR.2011.59330958

Smith, W. K., \& Tushman, M. L. (2005). Managing Strategic Contradictions: A Top Management Model for Managing Innovation Streams. Organization Science, 16(5), 522 536. doi: $10.1287 /$ orsc. 1050.0134

Stevens, J. (2010). The Power Path: The Shaman's Way to Success in Business and Life. New World Library.

Stoltzfus, K., Stohl, C., \& Seibold, D. R. (2011). Managing organizational change: paradoxical problems, solutions, and consequences. Journal of Organizational Change Management, 24(3), 349-367. doi: http://dx.doi.org.proxy.uwasa.fi/10.1108/09534811111132749

Sundaramurthy, C., \& Lewis, M. (2003). Control and collaboration: Paradoxes of governance. Academy of Management. The Academy of Management Review, 28(3), 397-415.

Wit, B. de, \& Meyer, R. (2010). Strategy Synthesis: Resolving Strategy Paradoxes to Create Competitive Advantage. Cengage Learning EMEA.

Woodward, J. (1965). Industrial organization: theory and practice. London Oxford University Press. Retrieved from https://trove.nla.gov.au/version/209714433 